Article

\title{
Structural and Optical Characterization of ZnS Ultrathin Films Prepared by Low-Temperature ALD from Diethylzinc and 1.5-Pentanedithiol after Various Annealing Treatments
}

\author{
Maksymilian Włodarski ${ }^{1}$, Urszula Chodorow ${ }^{2}$, Stanisław Jóźwiak ${ }^{3}{ }^{\circledR}$, Matti Putkonen ${ }^{4,+}{ }^{\oplus}$, \\ Tomasz Durejko ${ }^{3, *}$, Timo Sajavaara ${ }^{5}$ and Małgorzata Norek ${ }^{3, *}$ \\ 1 Institute of Optoelectronics, Military University of Technology, Kaliskiego 2, 00-908 Warsaw, Poland; \\ maksymilian.wlodarski@wat.edu.pl \\ 2 Institute of Applied Physics, Military University of Technology, Kaliskiego 2, 00-908 Warsaw, Poland; \\ urszula.chodorow@wat.edu.pl \\ 3 Department of Advanced Materials and Technologies, Faculty of Advanced Technologies and Chemistry, \\ Military University of Technology, Kaliskiego 2, 00-908 Warsaw, Poland; stanislaw.jozwiak@wat.edu.pl \\ 4 VTT Technical Research Centre of Finland, Biologinkuja 5, Espoo, P.O. Box 1000, FI-02044 VTT, Espoo, \\ Finland; matti.putkonen@helsinki.fi \\ 5 Department of Physics, University of Jyväskylä, P.O. Box 35, FI-40014, Jyväskylä, Finland, \\ timo.sajavaara@jyu.fi \\ * Correspondence: tomasz.durejko@wat.edu.pl (T.D.); malgorzata.norek@wat.edu.pl or \\ mnorek73@gmail.com (M.N.); Tel.: +48-261-837-135 (T.D.); +48-261-839-350 (M.N.) \\ † Current address: Department of Chemistry, University of Helsinki, P.O. Box 55, FI-00014 Helsinki, Finland. \\ Received: 15 July 2019; Accepted: 26 September 2019; Published: 30 September 2019 \\ check for \\ updates
}

\begin{abstract}
The structural and optical evolution of the $\mathrm{ZnS}$ thin films prepared by atomic layer deposition (ALD) from the diethylzinc (DEZ) and 1,5-pentanedithiol (PDT) as zinc and sulfur precursors was studied. A deposited ZnS layer (of about $60 \mathrm{~nm}$ ) is amorphous, with a significant $\mathrm{S}$ excess. After annealing, the stoichiometry improved for annealing temperatures $\geq 400{ }^{\circ} \mathrm{C}$ and annealing time $\geq 2 \mathrm{~h}$, and 1:1 stoichiometry was obtained when annealed at $500{ }^{\circ} \mathrm{C}$ for $4 \mathrm{~h}$. ZnS crystallized into small crystallites (1-7 nm) with cubic sphalerite structure, which remained stable under the applied annealing conditions. The size of the crystallites $(D)$ tended to decrease with annealing temperature, in agreement with the EDS data (decreased content of both $\mathrm{S}$ and $\mathrm{Zn}$ with annealing temperature); the $D$ for samples annealed at $600^{\circ} \mathrm{C}$ (for the time $\leq 2 \mathrm{~h}$ ) was always the smallest. Both reflectivity and ellipsometric spectra showed characteristics typical for quantum confinement (distinct dips/peaks in UV spectral region). It can thus be concluded that the amorphous $\mathrm{ZnS}$ layer obtained at a relatively low temperature $\left(150^{\circ} \mathrm{C}\right)$ from organic $\mathrm{S}$ precursor transformed into the layers built of small $\mathrm{ZnS}$ nanocrystals of cubic structure after annealing at a temperature range of $300-600^{\circ} \mathrm{C}$ under Ar atmosphere.
\end{abstract}

Keywords: atomic layer deposition (ALD); ZnS thin films; annealing; optical properties

\section{Introduction}

Zinc sulfide (ZnS) is one of the most important semiconductor, widely used in optoelectronics [1], lasers and photovoltaics [2], and photocatalysis [3]. The broad interest in $\mathrm{ZnS}$ has its origin in its properties. Among those properties, the wide and direct band gap (3.6-3.8 eV), high refractive index at room temperature (2.35), and high transmittance from visible to infrared (up to $12 \mu \mathrm{m}$ ) range, are the most attractive features $[4,5]$. Because of its high dielectric constant, excellent insulation properties and 
exceptional chemical stabilities, $\mathrm{ZnS}$ is considered as one of the most important passivation materials for semiconductor devices, especially for high-aspect ratio arrays based on $\mathrm{HgCdTe}$ [6,7]. Recently, $\mathrm{ZnS}$ quantum dots (QDs) have attracted considerable attention because of their broad biomedical (fluorescent probes) and sensor applications [8-12].

Future devices will require a technique with a perfect conformability to prepare $\mathrm{ZnS}$ layers on any complex surface. Atomic layer deposition (ALD) is a technique which is characterized by conformability incomparable to other techniques. Thanks to the self-limiting reaction at the surface between gaseous precursor molecules and chemical groups at a substrate [13,14], uniform layers can be grown on high aspect ratio and three-dimensionally-structured materials. ZnS was one of the earliest ALD-grown materials [15]. For preparing $\mathrm{ZnS}$ films by ALD, various zinc ( $\mathrm{Zn}$ )-precursors are used, including $\mathrm{ZnCl}_{2}$ [16,17], $\mathrm{ZnMe}_{2}$ [18,19], and $\mathrm{ZnEt}_{2}$ [20,21]. Among the Zn-precursors, diethylzinc $\left(\mathrm{ZnEt}_{2}\right.$ or DEZ) is particularly attractive, owing to its high vapor pressure and possibility to grow $\mathrm{ZnS}$ even at low deposition temperatures [22-24]. Unlike the wide range of accessible Zn-precursors, the S-precursor for $\mathrm{ZnS}$ is normally a $\mathrm{H}_{2} \mathrm{~S}$ compound [25], which is a very flammable and highly toxic gas. The toxicity and high tendency for contamination during deposition are strongly unwelcome, particularly for biomedical and sensing applications. Therefore, a safer S-precursor is especially needed. Recently, a new organic precursor, 1,5-pentanedithiol (PDT) for sulfur, was proposed by Ko et al. [26]. In their work, ZnS films were successfully grown on substrates with an atomic precision by repeating self-limiting chemisorption of DEZ and PDT as precursors of Zn and S, respectively. The obtained ZnS layers were, however, amorphous. Since most $\mathrm{ZnS}$ applications require crystalline or polycrystalline forms of $\mathrm{ZnS}$ (better for optical or opto-electrical performance), here, we studied the structural and optical evolution of the ZnS thin films prepared from DEZ and PDT after various annealing treatments. The structural changes of the ZnS films grown from the DEZ and PDT compounds have not been studied before. Moreover, ALD-deposited ZnS films are known to exist in both cubic (sphalerite) and hexagonal (wurtzite) crystal forms. It has been shown that the $\mathrm{ZnS}$ films deposited at temperatures lower $400{ }^{\circ} \mathrm{C}$ are mainly cubic, whereas the ones deposited above $400{ }^{\circ} \mathrm{C}$ are hexagonal $[20,27]$. The cubic and hexagonal phase can also coexist in a wide temperature range $\left(225-400^{\circ} \mathrm{C}\right)$ [24]. The aim of this study was also to check whether the $\mathrm{ZnS}$ layer undergoes a phase transformation from cubic to hexagonal crystallographic form under certain annealing conditions.

\section{Materials and Methods}

The $\mathrm{ZnS}$ thin films were deposited on silicon (Si) substrate by ALD technique using a Picosun SUNALE R-200 ALD reactor in a single wafer mode. Depositions were carried out at $150{ }^{\circ} \mathrm{C}$ with diethylzinc (DEZ) and 1,5-pentanedithiol (PDT) as precursors. PDT was evaporated from a Picohot 200 hot source held at $55^{\circ} \mathrm{C}$. DEZ was kept at $20^{\circ} \mathrm{C}$ to obtain surface-sufficient vapor pressure. Nitrogen (99.999\%) was used as a carrier and purging gas. Typical ALD deposition cycle consisted of DEZ pulse/purge/PDT pulse/purge with $0.2 \mathrm{~s} / 4 \mathrm{~s} / 0.3 \mathrm{~s} / 4 \mathrm{~s}$ timing, respectively. The $\mathrm{ZnS}$ film deposition rate was $0.09 \AA /$ cycle when measured after 500-2500 deposition cycles, resulting in film thickness of ca. $60 \mathrm{~nm}$.

The samples were annealed in a R80/750/12-B170 Nabertherm tube furnace under argon $(99.999 \%)$ atmosphere. Five samples were prepared and investigated: one sample without annealing ("as-deposited" sample) and four samples subjected to annealing at temperatures of 300, 400, 500, and $600^{\circ} \mathrm{C}$, with increasing annealing time ranging between $0.5-4 \mathrm{~h}$.

Microanalysis of chemical composition was done using a field-emission scanning electron microscope FE-SEM (FEI, Quanta) equipped with an energy-dispersive X-ray spectrometer (EDS). The chemical composition analysis was performed at $5 \mathrm{kV}$, magnification of 200, spot of 2.0, and with a constant distance of samples to the detector $(\mathrm{WD}=10)$. Each measurement was repeated three times and an average of the three measurements was taken to determine the chemical composition of the studied samples.

The composition of selected as-deposited thin films was determined by means of time-of-flight-elastic recoil detection analysis (TOF-ERDA) [28,29]. In this method, a heavy $11.9 \mathrm{MeV}^{63} \mathrm{Cu}^{6+}$ ion beam is directed 
to the sample and the time of flight (velocity) and energy of recoiled sample atoms are measured with a detector telescope at $41^{\circ}$ to the beam direction. Independent measurement of the velocity and energy of recoil atoms allows them to be differentiated according to their mass. The elemental depth profiles were determined by means of known geometry, elastic scattering cross-sections, and stopping forces [30].

$\mathrm{X}$-ray diffraction (XRD) analysis was performed using the grazing incidence X-ray diffraction (GI XRD) technique based on the $\mathrm{Co}_{\alpha 1}$ radiation $(\lambda=1.78892 \AA)$ using a Rigaku Ultima IV system with parallel beam mode of radiation. The crystal size and strain was calculated based on the Halder-Wagner theory (1) which, in contrast to the Williamson-Hall theory, offers more reliable data for reflections at low and intermediates angles than those at higher diffraction angles [31]:

$$
\left(\frac{\beta}{\tan \theta}\right)^{2}=\frac{K * \lambda}{D} * \frac{\beta}{\tan \theta * \sin \theta}+16 \varepsilon^{2}
$$

where:

$\beta$-integral breadth, depending on crystallite size and microstrain (in radians);

$\theta$-Bragg angle (in radians);

$\mathrm{K}$-shape factor (dimensionless);

$\lambda$-wavelength of the X-ray (in Angstrom);

D—crystallite size (in Angstrom);

$\varepsilon$-microstrain ( $\varepsilon=\frac{\Delta d}{d}$, where d is lattice plane spacing).

The ellipsometry measurements were carried out using a Sentech SE 850 variable angle spectroscopic ellipsometer. The data were acquired at an angle of incidence of $70^{\circ}$. The system is mainly used for thin-film characterization over a broad spectral range of $240-2400 \mathrm{~nm}$. As a result of ellipsometric measurements, two parameters $\Psi$ and $\Delta$ are obtained. Parameter $\Psi$ is the amplitude ratio of $\mathrm{p}$ - and s-polarizations, and $\Delta$ is the phase difference between $\mathrm{p}$ - and s-polarizations. The $\Psi$ and $\Delta$ parameters are defined from the ratio of the amplitude reflection $\left(r_{p}, r_{s}\right)$ or transmission $\left(t_{p}, t_{s}\right)$ coefficients for p- and s-polarizations [32]: $\frac{r_{p}}{r_{s}}=\tan (\Psi) \exp (\mathrm{i} \Delta)$ or $\frac{t_{p}}{t_{s}}=\tan (\Psi) \exp (\mathrm{i} \Delta)$.

Roughness of sample surfaces was determined using an optical profiler (Veeco / Wyko NT1100). For measurements, a phase shifting interferometry (PSI) mode was utilized because the thickness of thin films was ca. $60 \mathrm{~nm}$, thus we expected roughness to not be higher than a few nanometers. PSI mode is used to measure topographies of smooth surfaces (discontinuities on the surface have to be less than $150 \mathrm{~nm}$ ). The vertical resolution of measurements in PSI mode can achieve sub-nanometer scale. In this mode, a monochromatic light is used, and the surface topography is obtained by measuring the position and shape of the interference fringes on the sample.

The reflectance spectra of the samples annealed for $0.5 \mathrm{~h}$ were measured using a PerkinElmer Lambda 900 spectrometer with a PELA 1001 integrating sphere. Theses samples were measured in the $250-800 \mathrm{~nm}$ range. Other samples were measured using a PerkinElmer Lambda 650 spectrometer with a $150 \mathrm{~mm}$ integrating sphere in the $200-800 \mathrm{~nm}$ range with $1 \mathrm{~nm}$ step and resolution and $500 \mathrm{~ms}$ integration time. A beam condenser was used because of small dimensions of samples. The sphere was configured to collect both specular and diffused reflectance. Clean Si sample was used as 100\% reflection reference.

\section{Results and Discussion}

In Figure 1, SEM images (left column) and 3D outputs obtained with a Veeco/Wyko NT-1100 TM real-time optical surface profiler (right column) for $\mathrm{ZnS}$ film before annealing (Figure 1a,f), and after annealing for $1 \mathrm{~h}$ at $300^{\circ} \mathrm{C}$ (Figure $1 \mathrm{~b}, \mathrm{~g}$ ), $400{ }^{\circ} \mathrm{C}$ (Figure 1c,h), $500{ }^{\circ} \mathrm{C}$ (Figure 1d,i), and $600{ }^{\circ} \mathrm{C}$ (Figure 1e,j) respectively, are demonstrated. As can be seen, the surface of $\mathrm{ZnS}$ films is very smooth, without any visible cracks or defects, before as well as after annealing treatment. 

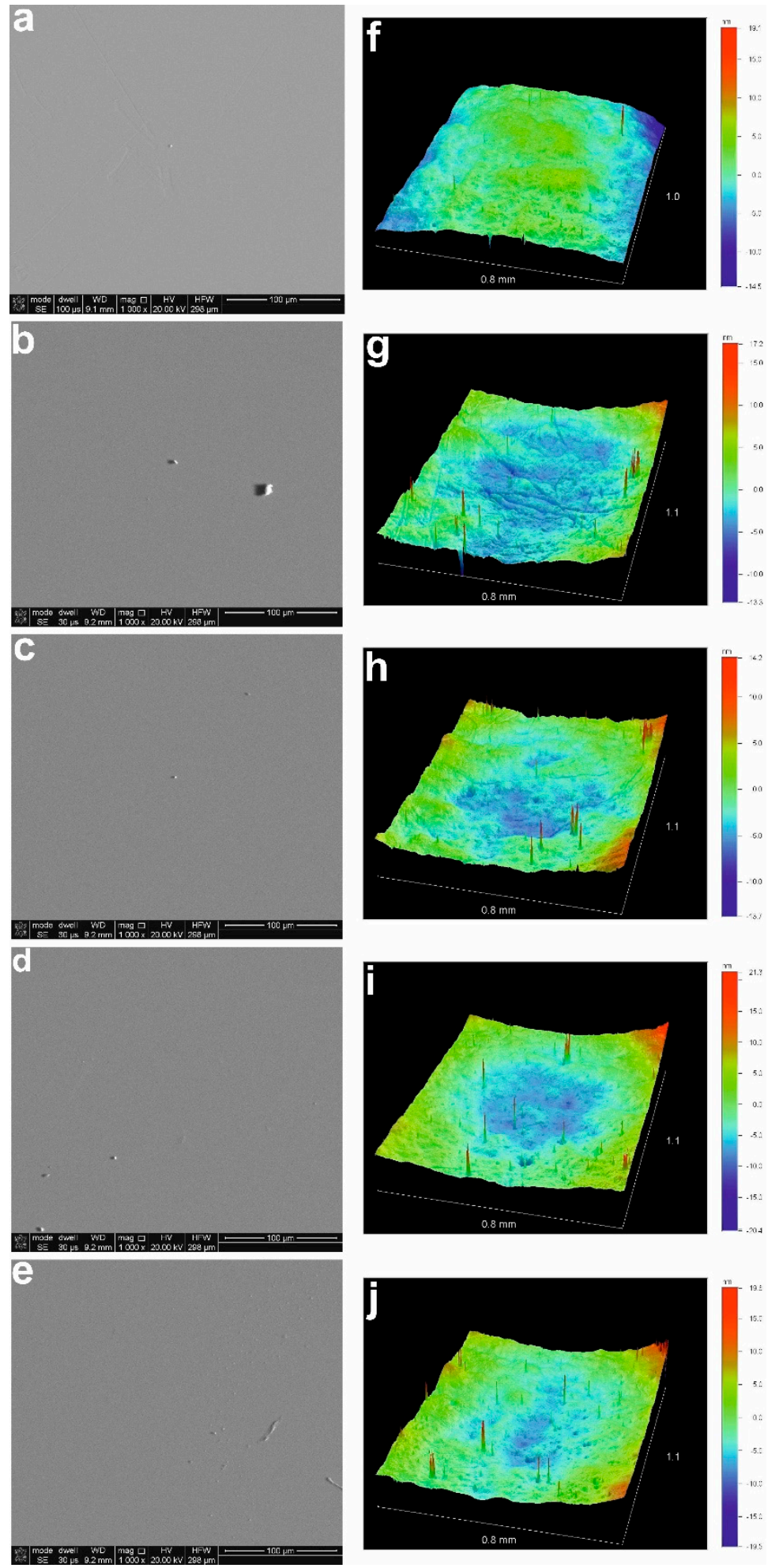

Figure 1. SEM images (left column) and 3D outputs obtained with Veeco/Wyko NT-1100 TM real-time optical surface profiler (right column) for $\mathrm{ZnS}$ film before annealing (a,f), and after annealing for $1 \mathrm{~h}$ at $300{ }^{\circ} \mathrm{C}(\mathbf{b}, \mathbf{g}), 400{ }^{\circ} \mathrm{C}(\mathbf{c}, \mathbf{h}), 500{ }^{\circ} \mathrm{C}(\mathbf{d}, \mathbf{i})$, and $600^{\circ} \mathrm{C}(\mathbf{e}, \mathbf{j})$, respectively.

Figure 2 shows the average content of zinc $(\mathrm{Zn})$, sulfur $(\mathrm{S})$, carbon $(\mathrm{C})$, and oxygen $(\mathrm{O})$ measured by EDS as a function of annealing temperature for various annealing times. The capital Roman letters $\mathrm{K}$ and $\mathrm{L}$ stand for the characteristic $\mathrm{X}$-ray lines resulting from electron transitions between inner orbits in a given element. According to TOF-ERDA measurements, as-deposited films had a 1:2 Zn:S ratio and 
relatively high $\mathrm{C}$ and $\mathrm{H}$ content of 51 an 27 at $\%$, respectively. This indicates relative low reactivity of the precursors, as depositions at $350^{\circ} \mathrm{C}$ resulted in 1:1 stoichiometric films with $\mathrm{H}$ and carbon content $<1.5$ and $<0.5$ at $\%$, respectively. Oxygen content was 3 at $\%$ when deposited at $150{ }^{\circ} \mathrm{C}$ and decreased to $1.5 \mathrm{at} \%$ at $350{ }^{\circ} \mathrm{C}$. However, a clear decrease of the $\mathrm{Zn}, \mathrm{S}$, and $\mathrm{C}$ concentration of films deposited at $150{ }^{\circ} \mathrm{C}$ during annealing was observed. During annealing, a drop of $\mathrm{C}$ content indicated the removal of remaining impurities from precursors with uncomplete reactions. The content of carbon dropped to below the detection limit after annealing at 400,500 , and $600{ }^{\circ} \mathrm{C}$ for 2 and $4 \mathrm{~h}$. The samples annealed for shorter times $(0.5$ and $1 \mathrm{~h})$ and at relatively low temperatures $\left(300{ }^{\circ} \mathrm{C}\right)$ nonetheless demonstrated a relatively large amount of carbon, suggesting that the annealing conditions were not sufficient to get rid of the residual carbon. Oxygen remained more-or-less at the similar level for all samples, except for the one with no presence of $\mathrm{Zn}, \mathrm{S}$, and C elements, which was most probably linked with an oxygenation of the $\mathrm{Si}$ substrates after exposure to air.
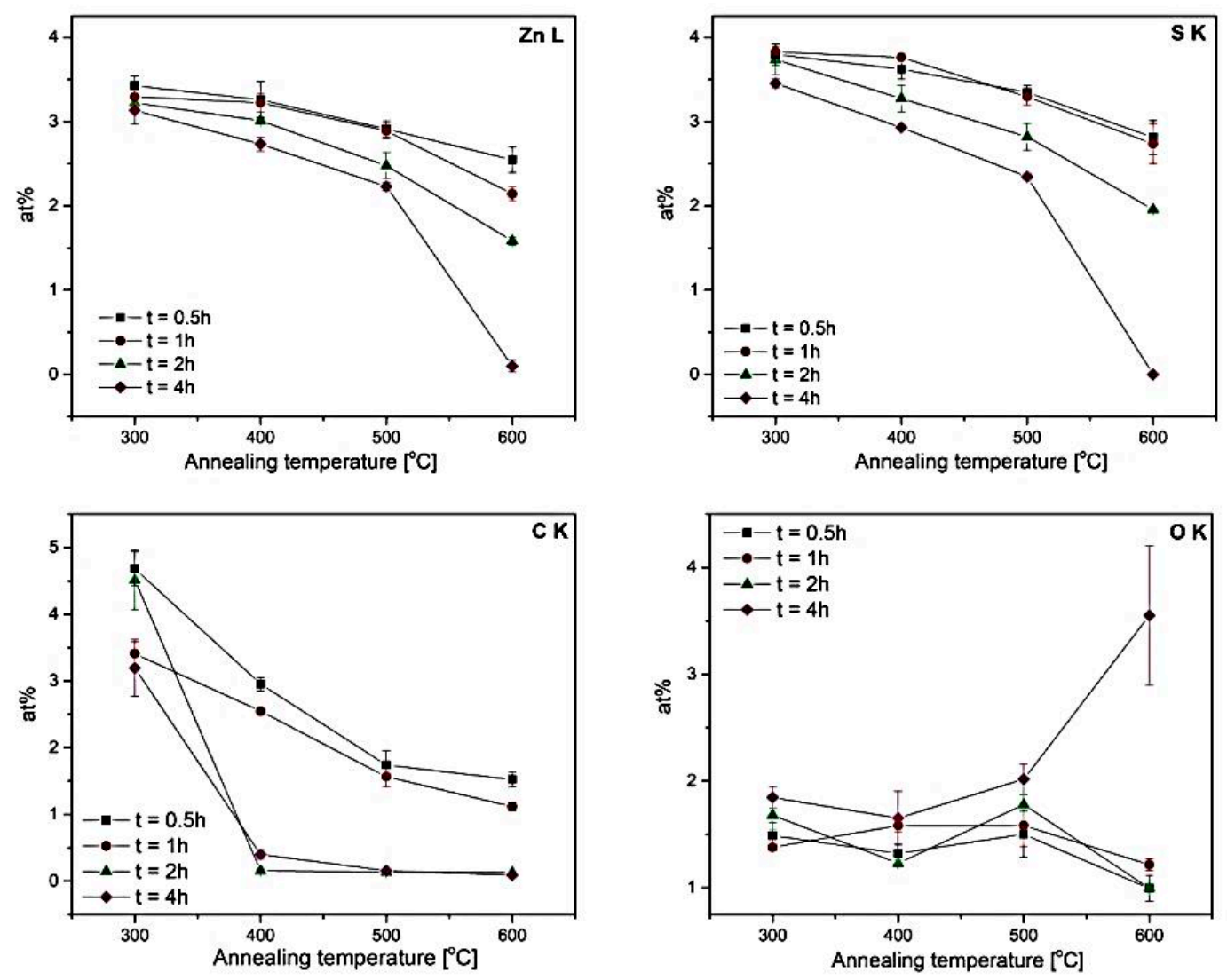

Figure 2. Energy-dispersive $\mathrm{X}$-ray spectrometer (EDS) elemental analysis at accelerating voltage of $5 \mathrm{kV}$ : the average $\mathrm{Zn}, \mathrm{S}, \mathrm{C}$, and $\mathrm{O}$ concentration (at $\%$ ) in the $\mathrm{ZnS}$ layers after annealing for 0.5, 1, 2, and $4 \mathrm{~h}$ as a function of annealing temperature.

In Table 1, the Zn and S contents in all samples are compared. First of all, the content of both Zn and $S$ dropped significantly in the samples subjected to annealing procedures when compared to the sample without annealing ("as deposited" sample). Moreover, the decrease of $S$ was definitely more pronounced (more than 2.5 times) compared with the decrease of $\mathrm{Zn}$, which may be associated with the lower vapor pressure of the former. Nevertheless, in most of the samples, an excess of S over $\mathrm{Zn}$ can be observed. The stoichiometry improved for annealing temperatures $\geq 400{ }^{\circ} \mathrm{C}$ and annealing time $\geq 2 \mathrm{~h}$, and it was almost perfect for the sample annealed at $500{ }^{\circ} \mathrm{C}$ for $4 \mathrm{~h}$. The excess of $\mathrm{S}$ over $\mathrm{Zn}$ in the samples annealed at shorter times $(0.5$ and $1 \mathrm{~h})$, accompanied by the relatively large amount of $\mathrm{C}$ in these samples, meaning that the precipitation of semiconductor nanocrystallites most probably occurred in a matrix of unreacted 1,5-pentanedithiol used as precursors of $S$. 
Table 1. The average $\mathrm{Zn}$ and S concentration (at $\%$ ) in $\mathrm{Zn}-\mathrm{S}$ thin films measured by EDS at $5 \mathrm{kV}$.

\begin{tabular}{|c|c|c|c|c|c|c|c|c|c|c|}
\hline \multirow[b]{2}{*}{ Temp } & \multicolumn{5}{|c|}{$\mathrm{Zn} \mathrm{L}$} & \multicolumn{5}{|c|}{ S K } \\
\hline & $\begin{array}{c}\text { As } \\
\text { Obtained }\end{array}$ & $0.5 \mathrm{~h}$ & $1 \mathrm{~h}$ & $2 \mathrm{~h}$ & $4 \mathrm{~h}$ & $\begin{array}{c}\text { As } \\
\text { Obtained }\end{array}$ & $0.5 \mathrm{~h}$ & $1 \mathrm{~h}$ & $2 \mathrm{~h}$ & $4 \mathrm{~h}$ \\
\hline- & $3.65 \pm 0.04$ & & & & & $8.75 \pm 0.23$ & & & & \\
\hline $300^{\circ} \mathrm{C}$ & & $3.42 \pm 0.11$ & $3.29 \pm 0.14$ & $3.22 \pm 0.06$ & $3.14 \pm 0.15$ & & $3.80 \pm 0.12$ & $3.83 \pm 0.06$ & $3.74 \pm 0.18$ & $3.45 \pm 0.05$ \\
\hline $400^{\circ} \mathrm{C}$ & & $3.26 \pm 0.22$ & $3.22 \pm 0.11$ & $3.01 \pm 0.04$ & $2.73 \pm 0.08$ & & $3.62 \pm 0.12$ & $3.76 \pm 0.02$ & $3.27 \pm 0.16$ & $2.93 \pm 0.01$ \\
\hline $500^{\circ} \mathrm{C}$ & - & $2.91 \pm 0.01$ & $2.89 \pm 0.09$ & $2.48 \pm 0.15$ & $2.23 \pm 0.05$ & - & $3.35 \pm 0.08$ & $3.30 \pm 0.01$ & $2.82 \pm 0.16$ & $2.35 \pm 0.04$ \\
\hline $600^{\circ} \mathrm{C}$ & & $2.55 \pm 0.15$ & $2.14 \pm 0.08$ & $1.58 \pm 0.05$ & $0.10 \pm 0.07$ & & $2.81 \pm 0.20$ & $2.74 \pm 0.23$ & $1.96 \pm 0.02$ & $0.00 \pm 0.00$ \\
\hline
\end{tabular}

Figure 3 shows XRD patterns of the samples annealed at temperatures $(T)$ of 300,400, 500, and $600^{\circ}$ as a function of annealing time. The sample before annealing (the "as-deposited" sample) was amorphous (no reflection in the XRD pattern was detected). The positions of the most pronounced peaks in the patterns corresponded to the (111), (220), and (311) crystallographic planes of the cubic ZnS (PDF number 01-072-4841). In some samples, the reflection from the Si substrate was also visible (marked by a red star, PDF Number 00-027-1402). The position of the (220) and (311) peaks varied in about 0.6 degrees, which can be ascribed to the presence of twinned sphalerites in some of the samples, or the fact that $\mathrm{ZnS}$ crystallites are built of a mixture of both sphalerites and densely twinned sphalerites [33,34]. It was suggested that the formation of the (111)-twinned sphalerite would occur at a high temperature and with a rapid crystal-growth rate [34]. Heating of the thin ZnS films after ALD deposition could favor the rapid crystal growth rate, and thus the conditions to form the twins. The peak designated by the question mark in brackets (the sample annealed at $300^{\circ} \mathrm{C}$ for $4 \mathrm{~h}$ ) could not be identified and was ascribed to neither of the possible crystallographic phases. It could, therefore, have come from an accidental reflection from the edge of the sample or from the sample holder. Moreover, from the XRD patterns, it can be inferred that the crystallinity of the samples improved systematically with annealing time and temperature (the XRD peak intensity increased). In general, the diffraction peak intensity was determined by the arrangement of atoms in the entire crystal $[35,36]$. Therefore, the sharper and more intense peaks meant a better ordering of atoms in the $\mathrm{ZnS}$ cubic cell. For the sample annealed at $600{ }^{\circ} \mathrm{C}$ for $4 \mathrm{~h}$, there was no XRD reflections, owing to the evaporation of the $\mathrm{Zn}$ and $\mathrm{S}$ elements under the prolonged annealing time at this high temperature (Figure 2).

In Table 2, apart from the peak position and broadening, the crystallite size $(D)$ and micro-strain values, calculated using the Halder-Wagner method, are gathered. The data are also illustrated in Figure 4. It can be seen that for the annealing time $\geq 2 \mathrm{~h}$, there was a tendency to decrease the crystallite size and lattice strain with annealing temperature. This tendency was, however, not so obvious for the samples annealed for shorter times $(0.5$ and $1 \mathrm{~h})$, although the $D$ for samples annealed at $600{ }^{\circ} \mathrm{C}$ (for the time $\leq 2 \mathrm{~h}$ ) was always the smallest. This may have been due to the presence of a large amount of carbon and the excess of sulfur in those samples (Figure 2), which could favor a formation different from cubic solid state phases. Owing to a strong repulsion between $S$ and C [37], and negligible mutual solubilities of $\mathrm{Zn}, \mathrm{S}$ [38], and C [39], a formation of graphite, monoclinic $\beta$-sulfur or hexagonal close-packed (hcp) zinc was more probable in this configuration. A small portion of these crystallographic forms, although not detectable by $\mathrm{XRD}$, could influence the peak shape from the cubic (111), (220), and (311) crystallographic planes and make it difficult to determine both crystallite size and lattice strain parameters.

Figure 5 illustrates the reflectance spectra of the $\mathrm{ZnS}$ thin films before and after annealing treatments. As can be seen, the reflectance spectrum of the amorphous, un-annealed ZnS layer was completely different than that for the annealed $\mathrm{ZnS}$ thin films. The reflectance spectrum of the amorphous $\mathrm{ZnS}$ thin film demonstrated a broad and distinct dip in the 450-500 $\mathrm{nm}$ range with a reflectance value of about 0.1. Similar reflectance minimums were observed for the $\mathrm{ZnS} / \mathrm{Au} / \mathrm{Ti}$ multilayer structure deposited on the Si substrate [40] and in electrodeposited $\mathrm{ZnS}$ thin films after annealing treatments [41]. Moreover, a significant transmittance of $\sim 70 \%$ at around $540 \mathrm{~nm}$ [42] and $~ 90 \%$ at around $550 \mathrm{~nm}$ [43] was observed for the ZnS layer thickness of 64 and $40 \mathrm{~nm}$, respectively. The broad minimum at around $500 \mathrm{~nm}$ in the reflectance spectra of un-annealed ZnS was most probably related with the absorption of the light by 
$\mathrm{Zn}^{2+}$ ions [44-47]. After annealing of the samples, the reflectance dip shifted to the UV region and became more narrow, with the reflectance values close to zero. This was certainly associated with the crystallization of the ZnS layers upon annealing, as observed by XRD measurements (Figure 3). Similar spectra were observed for the ZnS quantum dots (QDs) of the size ranging between $\sim 2$ and $5 \mathrm{~nm}$ [48-53]. Therefore, the presence of distinct dips in the UV spectral region strongly suggests quantum confinement of $\mathrm{ZnS}$ semiconductor. Upon annealing, the ZnS layer seemingly crystallizes into small nanocrystals.

Moreover, sharp peaks appearing below $300 \mathrm{~nm}$ indicated a presence of reasonably monodispersed particle size distribution. It can be also observed that for a given annealing time, the minimum had a tendency to shift towards lower wavelengths with increasing annealing temperature - it was always placed in the range of $250-300 \mathrm{~nm}$ for the annealing temperatures of $300-500{ }^{\circ} \mathrm{C}$, whereas it is shifted beneath $250 \mathrm{~nm}$ for the samples annealed at $600{ }^{\circ} \mathrm{C}$ (except for the sample annealed at $600{ }^{\circ} \mathrm{C}$ for $4 \mathrm{~h}$ ). In QDs, the band-gap between the valence state and the empty state increases as the nanocrystal becomes smaller [54]. Therefore, the shift of the peak in the reflectance spectra to the UV region indicates the decrease of the crystallite size and the increase of the band-gap. Although the general tendency of decreasing the crystallite size with annealing temperature as determined from the XRD data agreed well with the observed blue shift of the dip in the reflectance spectra, it is difficult to directly compare the change of crystal size from Table 2 with the position of the dips in Figure 5. This is because of a possible formation of $\mathrm{SiOx}$ layer of variable thickness on $\mathrm{Si}$ substrates that can affect the optical spectra. Furthermore, it has to be remembered that the Halder-Wagner model [31] is based on X-ray diffraction line broadening and provides more approximation than actual crystallite size values.
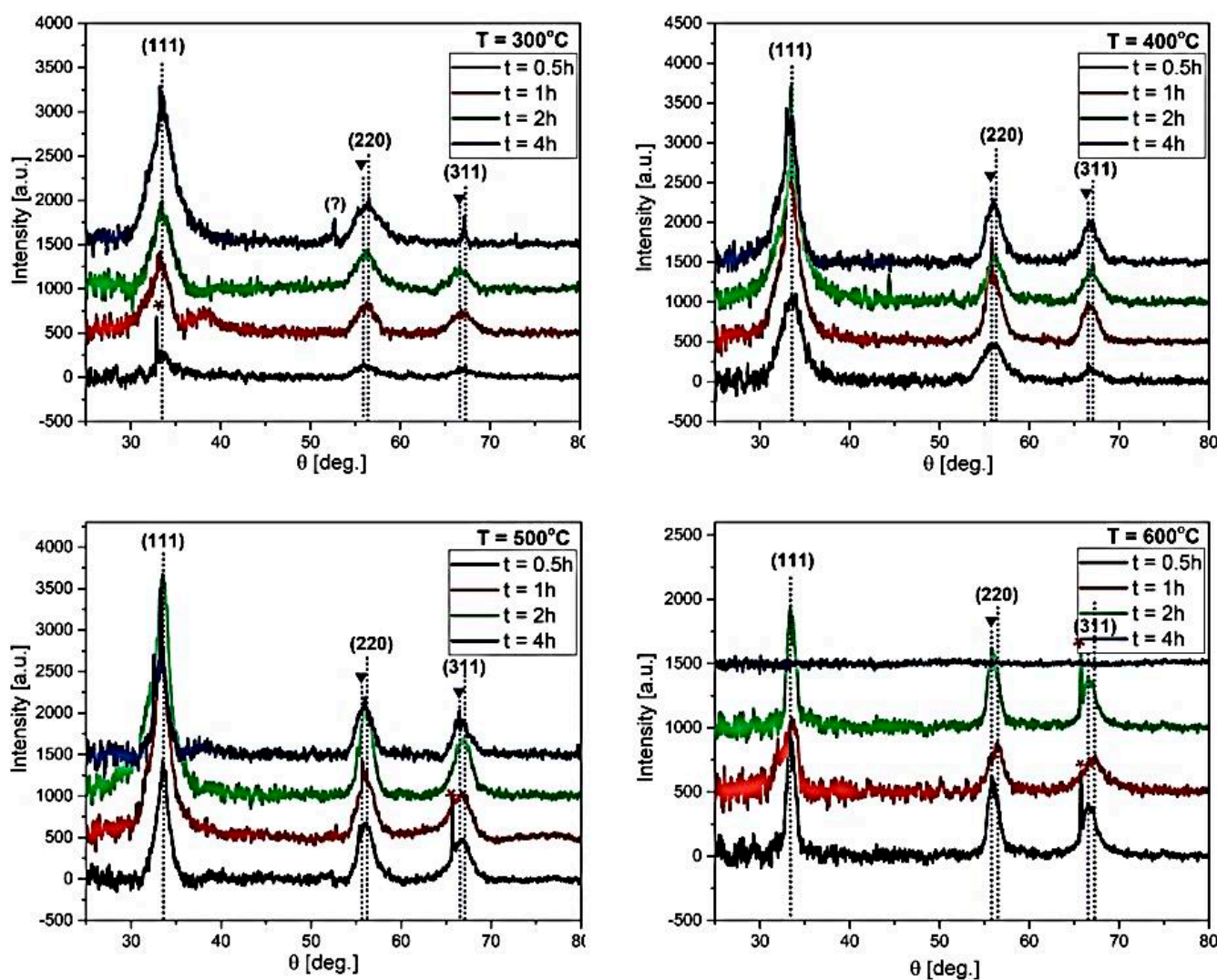

Figure 3. X-ray diffraction (XRD) pattern of the samples annealed at temperatures $300,400,500$, and $600{ }^{\circ} \mathrm{C}$ for various annealing times $(\mathrm{t})$ of $0.5,1,2$, and $4 \mathrm{~h}$. The red star symbol signifies the reflections originating from the Si substrate; the inverted triangles indicate the probable reflections from the twinned sphalerite. 
Table 2. Peak position and broadening, crystallite size, and micro-strain parameters determined from the XRD measurements of $\mathrm{ZnS}$ thin films after the annealing processes.

\begin{tabular}{|c|c|c|c|c|c|}
\hline \multirow{2}{*}{$0.5 \mathrm{~h}$} & \multicolumn{3}{|c|}{ Peak Position (Broadening) [2Ө] } & \multirow{2}{*}{ Crystallite Size $D$ [̊̊] } & \multirow{2}{*}{ Micro-Strain $e \times 10^{3}$} \\
\hline & (111) & (220) & (311) & & \\
\hline $300^{\circ} \mathrm{C}$ & $33.07(2.10)$ & $55.84(1.40)$ & $67.05(2.50)$ & 37.42 & 38.97 \\
\hline $400{ }^{\circ} \mathrm{C}$ & $33.71(3.00)$ & $56.31(02.44)$ & $66.56(1.00)$ & 53.85 & 51.42 \\
\hline $500{ }^{\circ} \mathrm{C}$ & 33.65 (1.89) & 55.98 (2.02) & 66.69 (1.20) & 33.73 & 36.14 \\
\hline $600^{\circ} \mathrm{C}$ & $33.36(1.76)$ & $56.08(1.90)$ & $66.92(1.62)$ & 30.65 & 28.28 \\
\hline \multirow{2}{*}{$1 \mathrm{~h}$} & \multicolumn{3}{|c|}{ Peak position (broadening) [2 $\theta]$} & \multirow{2}{*}{ Crystallite size $D[\AA ̊]$} & \multirow{2}{*}{ Micro-Strain $e \times 10^{3}$} \\
\hline & (111) & (220) & (311) & & \\
\hline $300{ }^{\circ} \mathrm{C}$ & 33.50 (3.19) & $56.31(2.54)$ & $66.84(3.50)$ & 56.61 & 47.50 \\
\hline $400^{\circ} \mathrm{C}$ & $33.18(1.99)$ & $55.37(1.80)$ & $66.59(2.01)$ & 35.07 & 36.32 \\
\hline $500{ }^{\circ} \mathrm{C}$ & 33.28 (1.69) & $56.00(2.07)$ & 66.97 (3.02) & 23.93 & 69.42 \\
\hline $600^{\circ} \mathrm{C}$ & $33.94(2.10)$ & $56.57(1.89)$ & $67.30(2.08)$ & 37.09 & 37.91 \\
\hline \multirow{2}{*}{$2 \mathrm{~h}$} & \multicolumn{3}{|c|}{ Peak position (broadening) $[2 \theta]$} & \multirow{2}{*}{ Crystallite size $D[\AA ̊]$} & \multirow{2}{*}{ Micro-Strain $e \times 10^{3}$} \\
\hline & (111) & (220) & (311) & & \\
\hline $300^{\circ} \mathrm{C}$ & $33.40(3.85)$ & $56.19(2.00)$ & $66.61(2.80)$ & 70.52 & 65.10 \\
\hline $400^{\circ} \mathrm{C}$ & $33.45(1.75)$ & $56.11(2.12)$ & $66.75(2.20)$ & 27.69 & 36.32 \\
\hline $500^{\circ} \mathrm{C}$ & $33.51(1.83)$ & $56.04(1.79)$ & $67.02(2.28)$ & 30.81 & 12.50 \\
\hline $600{ }^{\circ} \mathrm{C}$ & $33.30(0.60)$ & $55.76(0.69)$ & $66.50(1.00)$ & 08.93 & 33.91 \\
\hline \multirow{2}{*}{$4 \mathrm{~h}$} & \multicolumn{3}{|c|}{ Peak position (broadening) [2 $2 \theta]$} & \multirow{2}{*}{ Crystallite size $D[\AA ̊]$} & \multirow{2}{*}{ Micro-Strain $e \times 10^{3}$} \\
\hline & (111) & $(220)$ & (311) & & \\
\hline $300^{\circ} \mathrm{C}$ & $33.27(2.21)$ & $55.84(1,80)$ & $67.05(1.43)$ & 40.04 & 46.90 \\
\hline $400^{\circ} \mathrm{C}$ & $33.12(1.83)$ & 55.89 (2.06) & 66.62 (1.97) & 30.87 & 10.61 \\
\hline $500^{\circ} \mathrm{C}$ & $33.35(1.90)$ & $55.82(2.02)$ & $66.41(2.23)$ & 31.71 & 05.00 \\
\hline $600^{\circ} \mathrm{C}$ & - & - & - & - & - \\
\hline
\end{tabular}

a

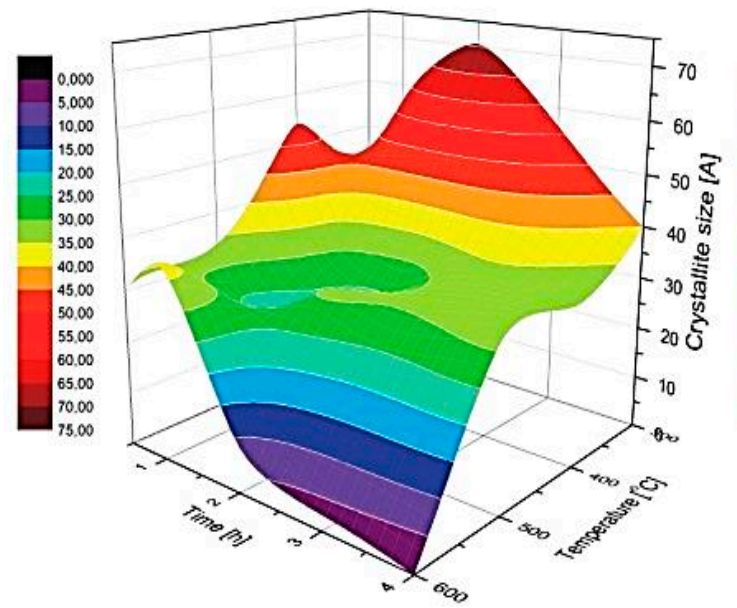

b

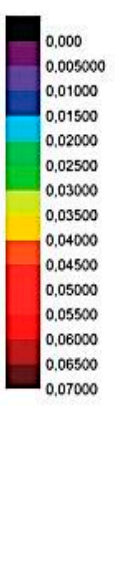

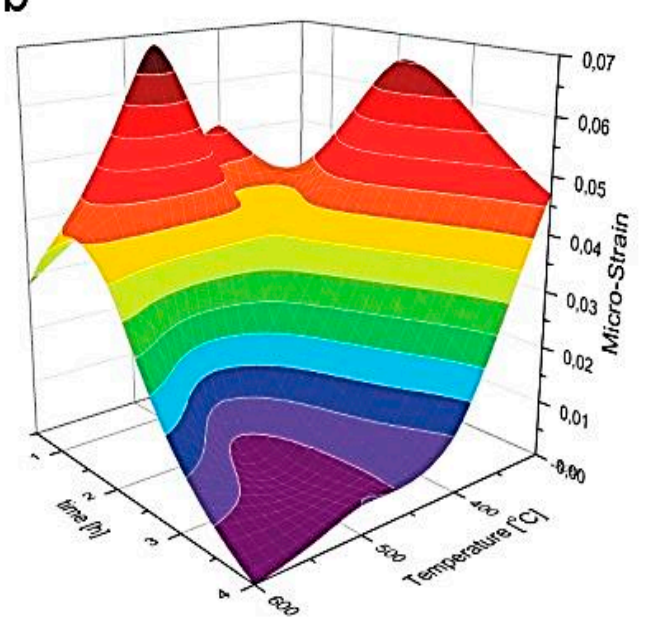

Figure 4. 3D graphs representing crystallite size (a) and micro-strain (b) as a function of annealing time and temperature for the studied $\mathrm{ZnS}$ thin films. 

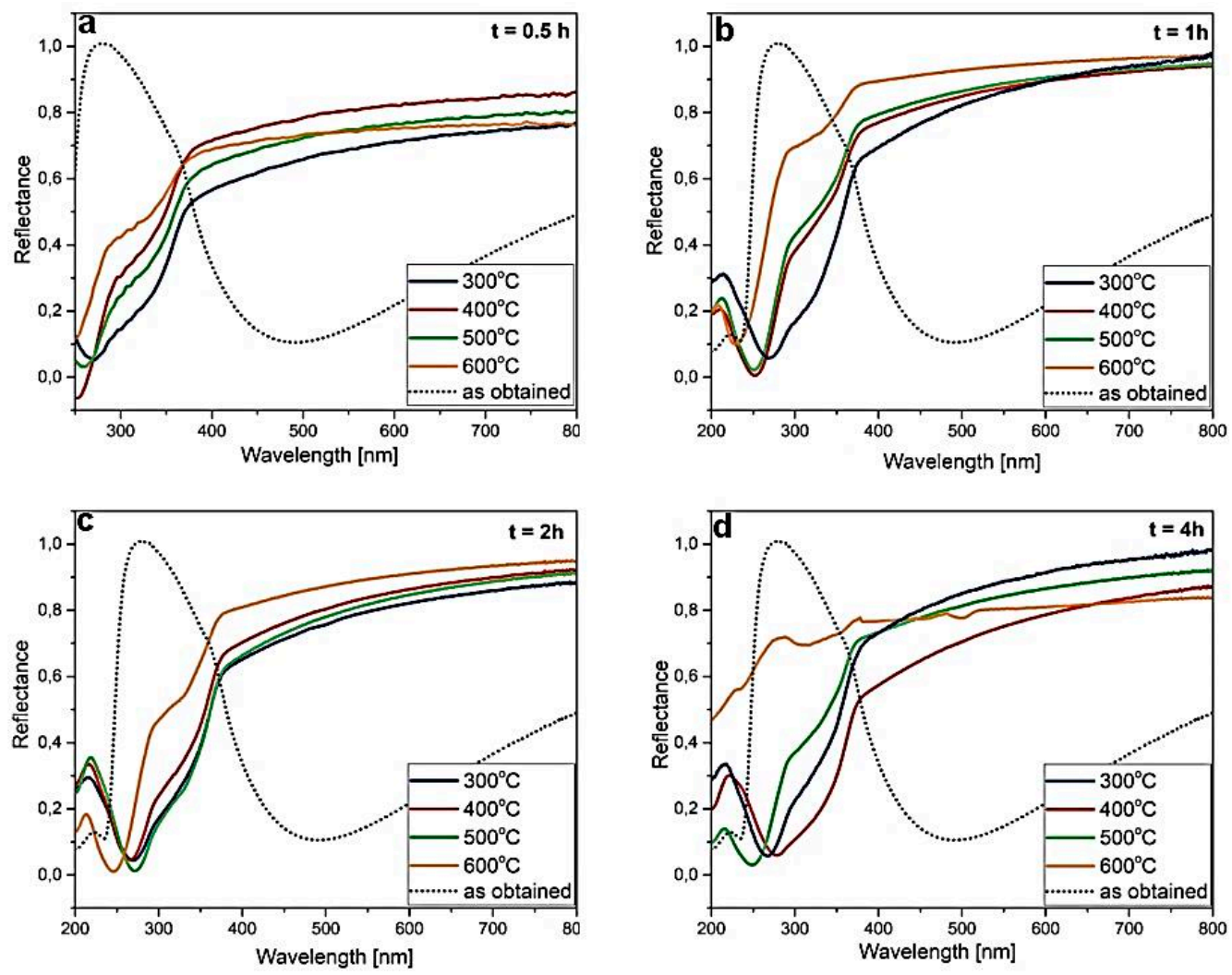

Figure 5. Reflectance spectra of the $\mathrm{ZnS}$ thin films before annealing (as obtained), and annealed at $300{ }^{\circ} \mathrm{C}, 400{ }^{\circ} \mathrm{C}, 500{ }^{\circ} \mathrm{C}$, and $600{ }^{\circ} \mathrm{C}$ for $0.5(\mathbf{a}), 1$ (b), 2 (c), and $4 \mathrm{~h}(\mathrm{~d})$.

In Figures 6 and 7, spectroscopic ellipsometry data $(\Psi, \Delta)$ of $\mathrm{ZnS}$ films before and after annealing are shown. Ellipsometry measures the change in polarized light upon light reflection on a sample (or light transmission by a sample). When light scattering by surface roughness reduces the reflected light intensity severely, ellipsometry measurement becomes difficult, as ellipsometry determines a polarization state from its light intensity. Therefore, if the size of the surface roughness is more than $\sim 30 \%$ of a measurement wavelength, the measurement error increases [55]. The RMS (root mean square) surface roughness of ZnS layers was in the range of $2-5 \mathrm{~nm}$ (Table 3); therefore, much below the 30\% mark. It can thus be concluded that the surface roughness was not a restriction in the studied cases.

In general, the interpretation of measurement results is rather difficult from the absolute values of $(\Psi, \Delta)$. Thus, construction of an optical model is required for data analysis. The spectral dependencies of $(\Psi, \Delta)$ of amorphous ZnS layer were successfully fitted with the Sellmeier dispersion model to extract the layer thickness and refractive index ( $n$ ) (Figure 5). The Sellmeier model is described by Equation (2) [56]:

$$
n^{2}(\lambda)=1+\frac{A \lambda^{2}}{\lambda^{2}-B^{2}}, k=0
$$

where $\lambda$ is the wavelength, $\mathrm{A}$ and $\mathrm{B}$ are fitting parameters, and $k$ is the extinction coefficient.

The ellipsometric analysis was done by taking into account a three-layer model: upper (rough) layer (modeled with effective medium approximation, EMA), middle - ZnS layer (Sellmeier model), and silicon substrate (fixed $n$ ). On the basis of the analysis, the best fit was obtained for $\mathrm{A}=2.134$ and $\mathrm{B}=0.006$, and the layer thickness of the $\mathrm{ZnS}$ was $60.9 \pm 0.5 \mathrm{~nm}$ (in agreement with the number of ALD cycles). The calculated refractive index of ZnS film was $n=1.7794 \pm 0.0031$ for $\lambda=632.8 \mathrm{~nm}$. The determined refractive index was lower than that for a bulk ZnS ( $n=2.3605$ for the $\lambda=632.8 \mathrm{~nm})$, which can be attributed to lower packing density of the amorphous thin $\mathrm{ZnS}$ film [57,58]. 

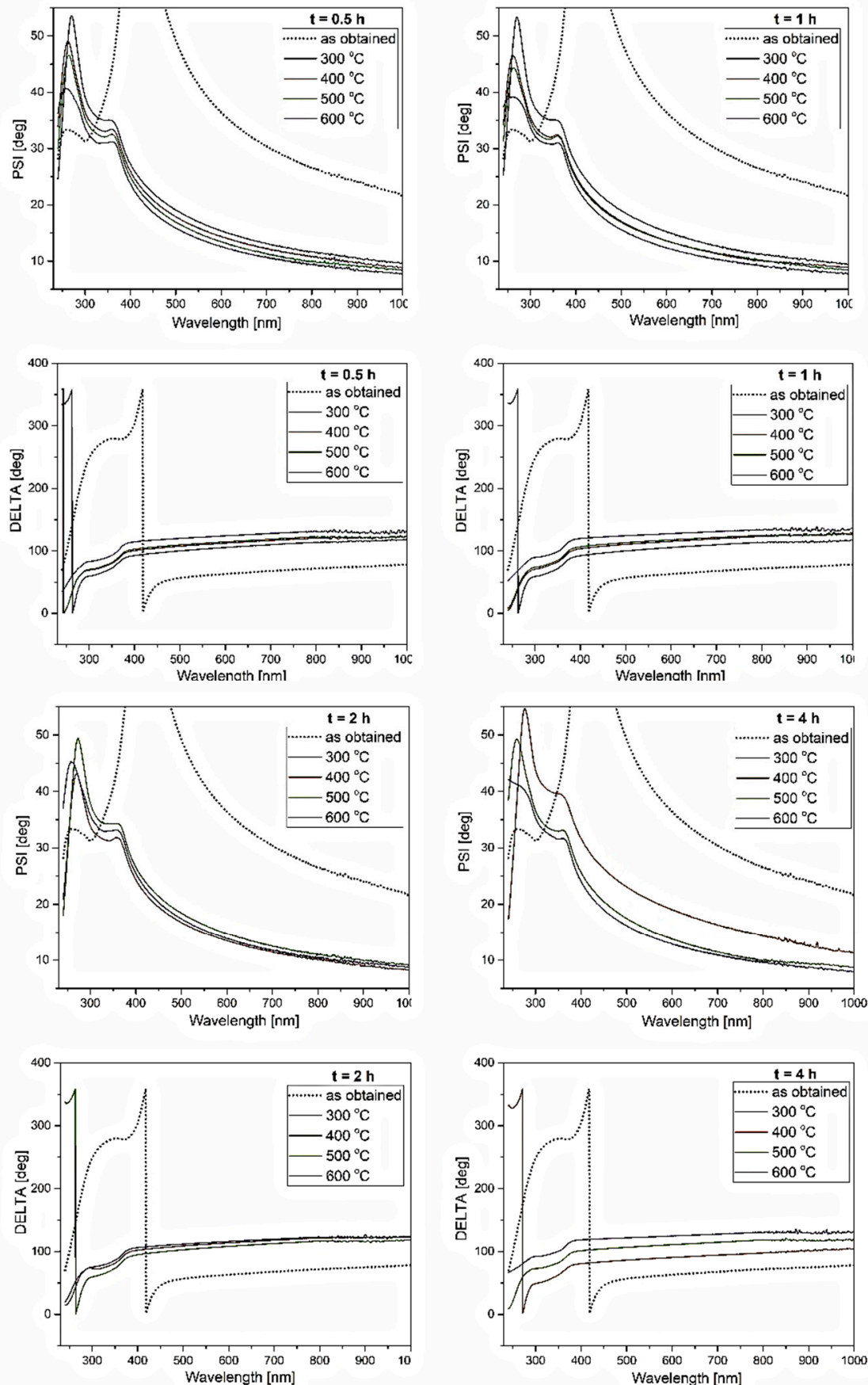

Figure 6. Spectral ellipsometric data $(\Psi, \Delta)$ of $\mathrm{ZnS}$ thin films before and after various annealing procedures. 

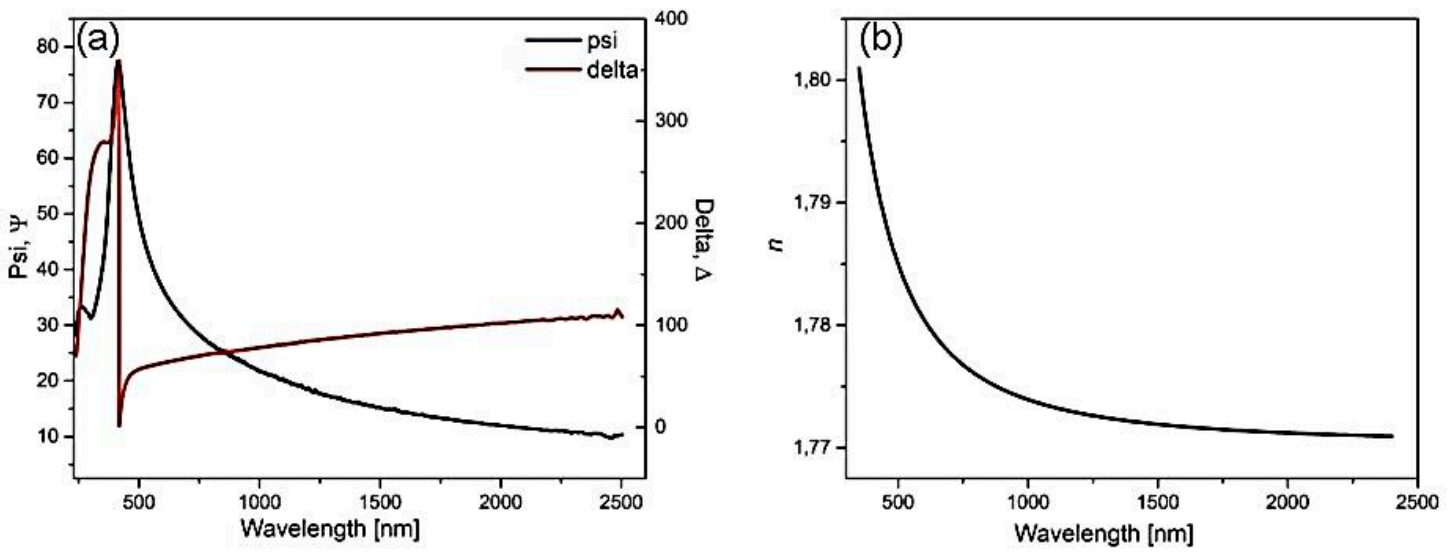

Figure 7. Spectral ellipsometric data $(\Psi, \Delta)$ of $\mathrm{ZnS}$ thin film before annealing (a) and refractive index (n) extracted from the spectral dependencies of the $(\Psi, \Delta)(\mathbf{b})$.

Table 3. RMS (root mean square) roughness (nm) for the studied $\mathrm{ZnS}$ thin films.

\begin{tabular}{cccccc}
\hline Temp & As Obtained & $\mathbf{0 . 5} \mathbf{h}$ & $\mathbf{1} \mathbf{~ h}$ & $\mathbf{2} \mathbf{h}$ & $\mathbf{4} \mathbf{~ h}$ \\
\hline- & 2.16 & - & - & - & - \\
$300^{\circ} \mathrm{C}$ & & 1.56 & 4.77 & 2.59 & 4.30 \\
$400^{\circ} \mathrm{C}$ & & 2.82 & 3.90 & 2.58 & 3.54 \\
$500{ }^{\circ} \mathrm{C}$ & - & 2.32 & 3.54 & 2.28 & 2.12 \\
$600{ }^{\circ} \mathrm{C}$ & & 1.47 & 3.79 & 2.44 & 3.74 \\
\hline
\end{tabular}

In Figure 6, the spectral ellipsometric data of the annealed $\mathrm{ZnS}$ thin films are compared with the $(\Psi, \Delta)$ of $\mathrm{ZnS}$ thin films before annealing. From the measured $(\Psi, \Delta)$ spectra it can be inferred that the optical features of ZnS layers changed significantly after annealing. In particular, the amplitude of the $\Psi$ oscillation (peak) decreased and shifted together with $\Delta$ to the UV spectral region. It was shown previously that both parameters $(\Psi, \Delta)$ shifted towards a shorter wavelength as the refractive index $(n)$ and film thickness $(t)$ decreased; however, as compared to $\Psi$, the $\Delta$ was more sensitive to the changes of both $n$ and $t$ [59]. The decrease of ZnS layer thickness after annealing would agree with EDS analysis (evaporation of residual precursor and/or other elements, Figure 2). Thickness-dependent interference between multiple reflections from different interfaces was not visible in these cases, because of the small film thickness. Moreover, in the high-energy region, optical interference was negligible because light absorption in samples generally increased and penetration depth of light became smaller. From the analysis of this energy region, band structure and effect of surface roughness can be studied [55]. This region was very similar to the reflectivity spectra presented in Figure 7. Particularly, the peak in $\Psi(\lambda)$ spectra behaved exactly the same as the dip in the reflectivity spectra-it tended to shift towards shorter wavelengths with annealing temperature, suggesting a decrease in the particle size (along with the layer thickness decrease) and the increase of the bandgap. Therefore, the ellipsometric data corroborated the assumption that a ZnS layer after ALD deposition at a relatively low temperature crystallizes into small $\mathrm{ZnS}$ nanocrystals of cubic structure after annealing at temperatures in the range of $300-600{ }^{\circ} \mathrm{C}$, with optical characteristics typical for quantum confinement.

The ellipsometric data of the annealed samples could not be fitted with the three-layer model; thus, other models were tested [60-63]. The best fit was obtained by taking into account the four-layer model: upper - rough layer (modeled with effective medium approximation, EMA), ZnS layer (Cody-Lorenz function), SiOx layer (Sellmeier model), and silicon substrate (fixed $n$ ). Both Cody-Lorenz (CL) as well as Tauc-Lorenz (TL) models were applied for amorphous and polycrystalline semiconductor thin films, having strong interband transitions; however, the CL is considered to be more accurate because of an Urbach absorption tail and modified density of states [64,65]. In this work, the CD model was found to yield better values of optical constants and lower mean square error (MSE), as compared to the TL model. The resulted parameters are gathered in Table S1 (Supplementary Materials). As expected, 
thickness $(t)$ of the ZnS layer dropped significantly after annealing-for a given annealing time, $t$ tended to decrease with the annealing temperature (Figure 8).

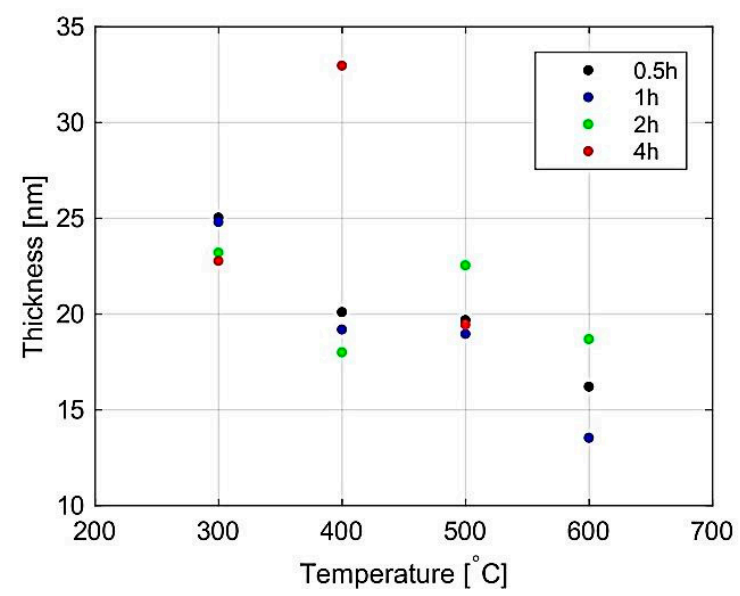

Figure 8. Thickness of the $\mathrm{ZnS}$ films as a function of annealing temperature for a given annealing time extracted from the spectral dependencies of the $(\Psi, \Delta)$.

In Figure 9, the spectral dependencies of refractive index $(n)$ extracted from the spectral dependencies of the $(\Psi, \Delta)$ presented in Figure 6 are provided (except for the sample annealed at $600{ }^{\circ} \mathrm{C}$ for $4 \mathrm{~h}$ where the amount of $\mathrm{Zn}$ and S elements were close to zero, as determined by the EDS analysis). It can be seen that there was a significant increase of $n$ after annealing. In some cases, $n$ became close to that of the bulk ZnS. However, $n$ did not show any strict dependence on the applied annealing parameters, although $n$ for the sample annealed at $600^{\circ} \mathrm{C}$ was always the smallest. This was probably caused by a complexity and inhomogeneity of the films (the presence of ZnS nanocrystals embedded in a mixture of various phases) that could not be included in this simplistic four-layer model.
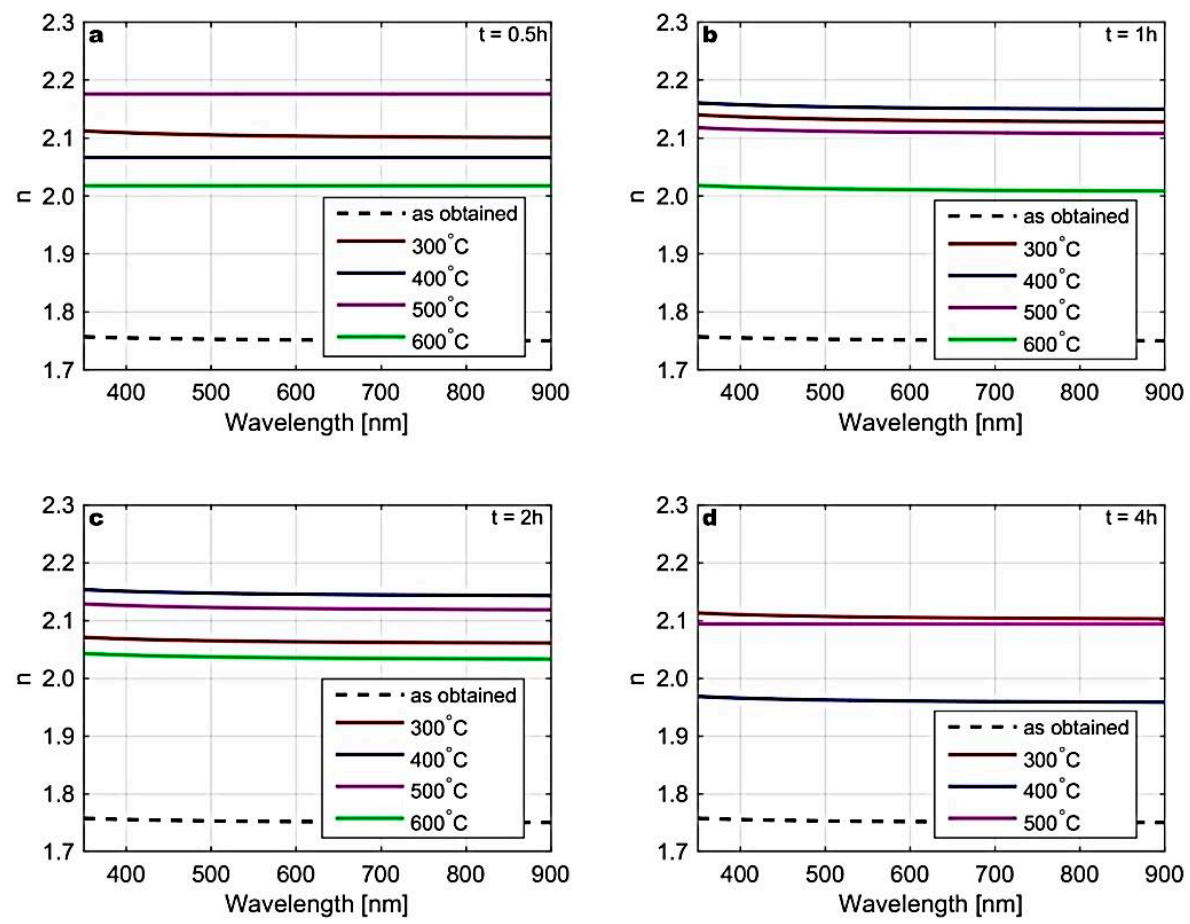

Figure 9. Refractive index $(n)$ extracted from the spectral dependencies of the $(\Psi, \Delta)$ measured for the $\mathrm{ZnS}$ thin films before annealing (as obtained), and annealed at $300{ }^{\circ} \mathrm{C}, 400{ }^{\circ} \mathrm{C}, 500{ }^{\circ} \mathrm{C}$, and $600{ }^{\circ} \mathrm{C}$ for 0.5 (a), 1 (b), 2 (c), and $4 \mathrm{~h}(\mathbf{d})$. 


\section{Conclusions}

ALD of ZnS layer from the diethylzinc and 1,5-pentanedithiol at $150{ }^{\circ} \mathrm{C}$ resulted in growth of an amorphous layer with a significant excess of $\mathrm{S}$ over $\mathrm{Zn}$ element. After annealing, the $\mathrm{S}$ excess in films was maintained; however, the stoichiometry improved for annealing temperatures $\geq 400{ }^{\circ} \mathrm{C}$ and annealing time $\geq 2 \mathrm{~h}$, and it was almost stoichiometric for the films annealed at $500{ }^{\circ} \mathrm{C}$ for $4 \mathrm{~h}$. For annealing at $600{ }^{\circ} \mathrm{C}$ for $4 \mathrm{~h}$, the $\mathrm{Zn}$ and S elements completely evaporated. ZnS crystallized into small crystallites $(1-7 \mathrm{~nm})$ with cubic sphalerite structure. The cubic phase remained stable-ZnS film did not undergo a phase transformation from cubic to hexagonal form under the applied annealing conditions. The size of the crystallites $(D)$ tended to decrease with annealing temperature in agreement with the EDS data (decreased content of both $S$ and $\mathrm{Zn}$ with annealing temperature)-the $D$ for samples annealed at $600{ }^{\circ} \mathrm{C}$ (for the time $\leq 2 \mathrm{~h}$ ) was always the smallest. The reflectivity spectra of the ZnS thin films after annealing were characterized by distinct dips in the UV region. The position of the dip tended to shift towards shorter wavelengths, with the annealing temperature most probably owing to the decrease of the $\mathrm{ZnS}$ crystallite size and, consequently, a wider band-gap (for the samples annealed at $600{ }^{\circ} \mathrm{C}$ the dip was shifted below $250 \mathrm{~nm}$ ). Similar results were obtained from ellipsometric measurements, where the shift of the peak in $\Psi(\lambda)$, together with the shift of $\Delta$ to the UV spectral region, was observed for the annealed samples. The shift towards a shorter wavelength occurred when the refractive index $(n)$ and film thickness $(t)$ decreased. The thickness of the $\mathrm{ZnS}$ amorphous layer before annealing treatment was determined using the Sellmeier model and was around $60 \mathrm{~nm}$. The reduction of the film thickness implied a reduction in the size of the $\mathrm{ZnS}$ crystallites. Therefore, it can be concluded that the amorphous $\mathrm{ZnS}$ layer obtained at relatively low temperature $\left(150{ }^{\circ} \mathrm{C}\right)$ from organic S precursor transformed into the layers built of small ZnS nanocystals after annealing at a temperature range of $300-600{ }^{\circ} \mathrm{C}$ under Ar atmosphere, with optical characteristics typical for quantum confinement.

Supplementary Materials: The following are available online at http://www.mdpi.com/1996-1944/12/19/3212/s1, Table S1: The best fit parameters extracted from the spectral dependencies of the $(\Psi, \Delta)$ presented in Figure 7 using the four-layer model.

Author Contributions: Conceptualization, M.P. and M.N.; Data curation, M.N.; Formal analysis, M.W., U.C., S.J. and T.S.; Investigation, M.W., U.C., S.J. and T.D.; Methodology, M.W., U.C., S.J., M.P. and T.D.; Writing-original draft, M.N.; Writing-review \& editing, T.D. and M.N.

Funding: The Ministry of National Defense Republic of Poland Program-Research Grant Military University of Technology Project 13-995 supported this work. MP acknowledges funding from the Academy of Finland by the profiling action on Matter and Materials, grant no. 318913 and the through the project grant no. 288212.

Conflicts of Interest: The authors declare no conflict of interest.

\section{References}

1. Xiong, Q.; Chen, G.; Acord, J.D.; Liu, X.; Zengel, J.J.; Gutierrez, H.R.; Redwing, J.M.; Lew Yan Voon, L.C.; Lassen, B.; Eklund, P.C. Optical properties of rectangular cross-sectional ZnS nanowires. Nano Lett. 2004, 4, 1663-1668. [CrossRef]

2. Fang, X.; Wu, L.; Hu, L. ZnS nanostructure arrays: A developing material star. Adv. Mater. 2011, 23, 585-598. [CrossRef] [PubMed]

3. Zhang, H.; Chen, X.; Li, Z.; Kou, J.; Yu, T.; Zou, Z. Preparation of sensitized ZnS and its photocatalytic activity under visible light irradiation. J. Phys. D Appl. Phys. 2007, 40, 6846-6849. [CrossRef]

4. Ruffner, J.A.; Hilmel, M.D.; Mizrahi, V.; Stegeman, G.I.; Gibson, U. Effects of low substrate temperature and ion assisted deposition on composition, optical properties, and stress of $\mathrm{ZnS}$ thin films. J. Appl. Opt. 1989, 28, 5209-5214. [CrossRef] [PubMed]

5. Elidrissi, B.; Addou, M.; Regragui, M.; Bougrine, A.; Kachouane, A.J.; Bernède, C. Structure, composition and optical properties of ZnS thin films prepared by spray pyrolysis. Mater. Chem. Phys. 2001, 68, 175-179. [CrossRef] 
6. Bhan, R.K.; Srivastava, V.; Saxena, R.S.; Sareen, L.; Pal, R.; Sharma, R.K. Improved high resistivity ZnS films on $\mathrm{HgCdTe}$ for passivation of infrared devices. Infrared Phys. Technol. 2010, 53, 404-409. [CrossRef]

7. Sun, C.H.; Zhang, P.; Zhang, T.N.; Chen, X.; Chen, Y.Y.; Ye, Z.H. ZnS thin films grown by atomic layer deposition on GaAs and HgCdTe substrates at very low temperature. Infrared Phys. Technol. 2017, 85, 280-286. [CrossRef]

8. Pacheco, M.E.; Castells, C.B.; Bruzzone, L. Mn-doped ZnS phosphorescent quantum dots: Coumarins optical sensors. Sens. Actuators B Chem. 2017, 238, 660-666. [CrossRef]

9. Liu, X.; Yang, Y.; Li, Q.; Wang, Z.; Xing, X.; Wang, Y. Portably colorimetric paper sensor based on ZnS quantum dots for semi-quantitative detection of $\mathrm{Co}^{2+}$ through the measurement of grey level. Sens. Actuators B Chem. 2018, 260, 1068-1075. [CrossRef]

10. Borgohain, R.; Boruah, P.K.; Baruah, S. Heavy-metal ion sensor using capped ZnS quantum dots. Sens. Actuators B Chem. 2016, 226, 534-539. [CrossRef]

11. Wu, D.; Chen, Z. ZnS quantum dots as $\mathrm{pH}$ probes for study of enzyme reaction kinetics. Enzym. Microb. Technol. 2012, 51, 47-52. [CrossRef] [PubMed]

12. Mobarraz, M.; Ganjali, M.R.; Chaichi, M.J.; Norouzi, P. Functionalized ZnS quantum dots as luminescent probes for detection of amino acids. Spectrochim. Acta Part A Mol. Biomol. Spectrosc. 2012, 96, 801-804. [CrossRef] [PubMed]

13. Johnson, R.W.; Hultqvist, A.; Bent, S.F. A brief review of atomic layer deposition: From fundaments to applications. Mater. Today 2015, 17, 236-246. [CrossRef]

14. Knez, M.; Nielsch, K.; Niinisto, L. Synthesis and Surface engineering of complex nanostructures by atomic layer deposition. Adv. Mater. 2007, 19, 3425-3438. [CrossRef]

15. Ahvenniemi, E.; Akbashev, A.R.; Ali, S.; Bechelany, M.; Berdova, M.; Boyadjiev, S.; Cameron, D.C.; Chen, R.; Chubarov, M.; Cremers, V.; et al. Review article: Recommended reading list of early publications on atomic layer deposition-Outcome of the "Virtual Project on the History of ALD”. J. Vac. Sci. Technol. A 2017, 35, 10801. [CrossRef]

16. Szczerbakow, A.; Dynowska, E.; Godlewski, M.; Świątek, K. Monocrystalline ZnS-sphalerite films grown by atomic layer epitaxy in a gas flow system. J. Cryst. Growth 1998, 183, 708-710. [CrossRef]

17. Yun, S.J.; Dey, S.; Nam, K.S. Zinc sulfide and terbium-doped zinc sulfide films grown by traveling wave reactor atomic layer epitaxy. J. Korean Phys. Soc. 1998, 33, S454-S457.

18. Wu, Y.-H.; Toyoda, T.; Kawakami, Y.; Fujita, S. Atomic layer epitaxy of ZnS on GaAs substrates by metalorganic molecular beam epitaxy. Jpn. J. Appl. Phys. 1990, 29, L727-L730. [CrossRef]

19. Hsu, C.T. Epitaxial growth of II-VI compound semiconductors by atomic layer epitaxy. Thin Solid Film 1998, 335, 284-291. [CrossRef]

20. Kim, Y.S.; Yun, S.J. Studies on polycrystalline ZnS thin films grown by atomic layer deposition for electroluminescent applications. Appl. Surf. Sci. 2004, 229, 105-111. [CrossRef]

21. Yokoyama, M.; Chen, N.-T. ALE growth and optical characterization of ZnSe/ZnS strained quantum well structures on Si substrate. J. Cryst. Growth 2001, 223, 369-375. [CrossRef]

22. Tanskanen, J.T.; Bakke, J.R.; Bent, S.F.; Pakkanen, T.A. ALS growth characteristics of ZnS films deposited from organozinc and hydrogen sulfide precursors. Langmuir 2010, 26, 11899-11906. [CrossRef] [PubMed]

23. Xu, R.; Takoudis, C.G. Chemical passivation of GaSb-based surfaces by atomic layer depostied ZnS using diethyzinc and hydrogen sulfide. J. Vac. Sci. Technol. A 2012, 30, 1A145. [CrossRef]

24. Bakke, J.R.; King, J.S.; Jung, H.J.; Sinclair, R.; Bent, S.F. Atomic layer deposition of ZnS via in situ production of $\mathrm{H}_{2}$ S. Thin Solid Film 2010, 518, 5400-5408. [CrossRef]

25. Miikkulainen, V.; Leskelä, M.; Ritala, M.; Puurunen, R.L. Crystallinity of inorganic films grown by atomic layer deposition: Overview and general trends. J. Appl. Phys. 2013, 113, 21301. [CrossRef]

26. Ko, D.-H.; Kim, S.; Jin, Z.; Shin, S.; Lee, S.Y.; Min, Y.-S. A novel chemical route to atomic layer deposition of ZnS thin film from Diethylzinc and 1,5-Pentanedithiol. Bull. Korean Chem. Soc. 2017, 38, 696-699. [CrossRef]

27. Lahtinen, J.A.; Lu, A.; Tuomi, T.; Tammenmaa, M. Effect of growth temperature on the electronic energy band and crystal structure of ZnS thin films grown using atomic layer epitaxy. J. Appl. Phys. 1985, 58, 1851-1853. [CrossRef]

28. Putkonen, M.; Sajavaara, T.; Niinistö, L.; Keinonen, J. Analysis of ALD-processed thin films by ion-beam techniques. Anal. Bioanal. Chem. 2005, 382, 1791-1799. [CrossRef] 
29. Whitlow, H.J.; Possnert, G.; Petersson, C.S. Quantitative mass and energy dispersive elastic recoil spectrometry: Resolution and efficiency consideration. Nucl. Instrum. Meth. B 1987, 27, 448-457. [CrossRef]

30. Ziegler, J.F. SRIM. Available online: http://www.SRIM.org, (accessed on 29 April 2019).

31. Izumi, F.; Ikeda, T. Implementation of the Williamson-Hall and Halder-Wagner Methods into RIETAN-FP. Ann. Rep. Adv. Ceram. Res. Center Nagoya Inst. Technol. 2015, 3, 33-38.

32. Tompkins, H.G.; Irene, E.A. Handbook of Ellipsometry; William Andrew Inc.: Norwich, UK, 2005.

33. Dutková, E.; Daneu, N.; Lukáčová Bujňáková, Z.; Baláž, M.; Kováč, J.; Baláž, P. Mechanochemical synthesis and characterization of $\mathrm{CuInS}_{2} / \mathrm{ZnS}$ nanocrystals. Molecules 2019, 24, 1031. [CrossRef] [PubMed]

34. Nitta, E.; Kimata, M.; Hoshino, M.; Echigo, T.; Hamasaki, S.; Nishida, N.; Shimizu, M.; Akasaka, T. Crystal chemistry of $\mathrm{ZnS}$ minerals formed as high-temperature volcanic sublimates: Matraite identical with sphalerite. J. Miner. Petrol. Sci. 2008, 103, 145-151. [CrossRef]

35. Terohid, S.A.A.; Heidari, S.; Jafari, A.; Asgary, S. Effect of growth time on structural, morphological and electrical properties of tungsten oxide nanowire. Appl. Phys. A 2018, 124, 567. [CrossRef]

36. Frentrup, M.; Lee, S.-L.; Sahonta, L.Y.; Kappers, M.J.; Massabuau, F.; Gupta, P.; Oliver, R.A.; Humphreys, C.J.; Wallis, D.J. X-ray diffraction analysis of cubic zincblende III-nitrides. J. Phys. D Appl. Phys. 2017, 50, 433002. [CrossRef]

37. Tafwidli, F.; Kang, Y.-B. Thermodynamic modeling of Fe-C-S ternary system. ISIJ Int. 2017, 57, 782-790. [CrossRef]

38. Sharma, R.C.; Chang, Y.A. The S-Zn (sulfur-zinc) system. J. Phase Equilibr. 1996, 17, 261-266. [CrossRef]

39. MTDATA - Phase Diagram Software from the National Physical Laboratory. Available online: http: //resource.npl.co.uk/mtdata/phdiagrams/czn.htm (accessed on 29 April 2019).

40. Kim, K.-H.; Park, Q.-H. Maximal light-energy transfer through a dielectric/metal-layered electrode on a photoactive device. Opt. Express 2014, 22, 1963-1970. [CrossRef]

41. Zakerian, F.; Kafashan, H. Investigation the effect of annealing parameters on the physical properties of electrodeposited ZnS thin films. Superlattices Microstruct. 2018, 124, 92-106. [CrossRef]

42. Kedawat, G.; Kumar, P.; Vijay, Y.K.; Gupta, B.K. Fabrication of highly efficient resonant structure assisted ultrathin artificially stacked Ag/ZnS/Ag multilayer films for color filter applications. J. Mater. Chem. C 2015, 3, 6745-6754. [CrossRef]

43. Liu, X.; Cai, X.; Qiao, J.; Mao, J.; Jiang, N. The design of ZnS/Ag/ZnS transparent conductive multilayer films. Thin Solid Film 2003, 441, 200-206. [CrossRef]

44. Nouri, H.; Cadiou, C.; Lawson-Daku, L.M.; Hauser, A.; Chevreux, S.; Déchamps-Olivier, I.; Lachaud, F.; Ternane, R.; Trabelsi-Ayadi, M.; Chuburua, F.; et al. A modified cyclen azaxanthone ligand as a new fluorescent probe for Zn 2+. Dalton Trans. 2013, 42, 12157-12164. [CrossRef] [PubMed]

45. Mahiuddin, M.D.; Banerjee, M.; Shaikh, A.; Shyam, T.; Taniya, S.; Ghosh, A.; Adhikary, A.; Brandao, P.; Felix, V.; Das, D. Optical sensors for detection of nano-molar $\mathrm{Zn}^{2+}$ in aqueous medium: Direct evidence of probe- Zn2+ binding by single crystal X-ray structures. J. Photochem. Photobiol. A Chem. 2019, 368, 52-61. [CrossRef]

46. Wu, W.-N.; Mao, P.-D.; Wang, Y.; Zhao, X.-L.; Xu, Z.-Q.; Xu, Z.-H.; Xue, Y. Quinoline containing acetyl hydrazone: An easily accessible switch-on optical chemosensor for $\mathrm{Zn}^{2+}$. Spectrochim. Acta Part A Mol. Biomol. Spectrosc. 2018, 188, 324-331. [CrossRef] [PubMed]

47. Zhou, C.; Liu, H. A novel nanofibrous film chemosensor for highly selective and sensitive optical signaling of $\mathrm{Zn}^{2+}$. J. Braz. Chem. Soc. 2017, 28, 1947-1952. [CrossRef]

48. Al-Douri, Y.; Verma, K.D. Prakash, Deo optical investigations of blue shift in ZnS quantum dots. Superlattices Microstruct. 2015, 88, 662-667. [CrossRef]

49. Ashokkumar, M.; Boopathyraja, A. Structural and optical properties of Mg doped ZnS quantum dots and biological applications. Superlattices Microstruct. 2018, 113, 236-243. [CrossRef]

50. Horoz, S. Effect of $\mathrm{Eu}^{2+}$ doping on structural, optical, magnetic and photovoltaic properties of ZnS quantum dots. Superlattices Microstruct. 2017, 111, 1043-1049. [CrossRef]

51. Lu, S.H.; Chen, T.F.; Wang, A.J.; Wu, Z.L.; Wang, Y.S. Lattice and optical property evolution of ultra-small ZnS quantum dots grown from a single-source precursor. Appl. Surf. Sci. 2014, 299, 116-122. [CrossRef]

52. Navaneethan, M.; Archana, J.; Nisha, K.D.; Hayakawa, Y.; Ponnusamy, S.; Muthamizhchelvan, C. Synthesis of highly size confined ZnS quantum dots and its functional characteristics. Mater. Lett. 2012, 68, $78-81$. [CrossRef] 
53. Mashford, B.; Baldauf, J.; Nguyen, T.-L.; Funston, A.M.; Mulvaney, P. Synthesis of quantum dot doped chalcogenide glasses via sol-gel processing. J. Appl. Phys. 2011, 109, 94305. [CrossRef]

54. Reshma, V.G.; Mohanan, P.V. Quantum dots: Applications and safety consequences. J. Lumin. 2019, 205, 287-298. [CrossRef]

55. Fujiwara, H. Spectroscopic Ellipsometry: Principles and Applications; John Wiley \& Sons Ltd.: West Sussex, UK, 2007.

56. Ong, H.C.; Chang, R.P.H. Optical constants of wurtzite ZnS thin films determined by spectroscopic ellipsometry. Appl. Phys. Lett. 2001, 79, 3612-3614. [CrossRef]

57. Prathap, P.; Revathi, N.; Subbaiah, Y.P.V.; Reddy, K.T.R. Thickness effect on the microstructure, morphology and optoelectronic properties of ZnS films. J. Phys. Condens. Matter 2008, 20, 35205. [CrossRef]

58. Wu, X.; Lai, F.; Lin, L.; Zhuang, B.; Yan, Q.; Huang, Z. Optical inhomogeneity of ZnS films deposited by thermal evaporation. Appl. Surf. Sci. 2008, 254, 6455-6460. [CrossRef]

59. Nabok, A.; Tsargorodskaya, A. The method of total internal reflection ellipsometry for thin film characterisation and sensing. Thin Solid Film 2008, 516, 8993-9001. [CrossRef]

60. Prakash, D.; Aboraia, A.M.; El-Hagary, M.; Shaaban, E.R.; Verma, K.D. Determination of the optical constants and film thickness of ZnTe and ZnS thin films in terms of spectrophotometric and spectroscopic ellipsometry. Ceram. Int. 2016, 42, 2676-2685. [CrossRef]

61. En Naciri, A.; Ahmed, F.; Stchakovsky, M. Optical properties of ZnTe and ZnS nanocrystals by critical-points and Tauc-Lorentz models. Thin Solid Film 2011, 519, 2843-2846. [CrossRef]

62. Brakstad, T.; Hope, B.R.; Nematollahi, M.; Kildemo, M.; Podraza, N.J.; Ghimire, K.; Reenaas, T.W. Ellipsometric study of the optical response of ZnS:Cr for PV applications. Appl. Surf. Sci. 2017, 421, 315-319. [CrossRef]

63. Antonello, A.; Brusatin, G.; Guglielmi, M.; Martucci, A.; Bello, V.; Mattei, G.; Mazzoldi, P.; Pellegrini, G. Hybrid organic-inorganic ZnS-loaded nanocomposite films for stable optical coatings. Thin Solid Film 2010, 518, 6781-6786. [CrossRef]

64. Ferlauto, A.S.; Ferreira, G.M.; Pearce, J.M.; Wronski, C.R.; Collins, R.W.; Deng, X.; Ganguly, G. Analytical model for the optical functions of amorphous semiconductors from the near-infrared to ultraviolet: Applications in thin film photovoltaics. J. Appl. Phys. 2002, 92, 2424-2436. [CrossRef]

65. Jellison, G.E.; Modine, F.A. Parameterization of the optical functions of amorphous materials in the interband region. Appl. Phys. Lett. 1996, 69, 371-373. [CrossRef] 